\title{
The enhanced greenhouse effect and its impact on rural New Zealand
}

\section{Richard G. Heerdegen}

Department of Geography, Massey University, Palmerston North

ABSTRACT A rise in temperature of 0.5 to $1.0^{\circ} \mathrm{C}$ in the past century, resulting from an increased volume of atmospheric 'greenhouse' gases, has been caused by the burning of fossil fuels, industrial processes and agricultural activities. The consequences of this enhanced greenhouse effect by 2050 will be a $2.0^{\circ} \mathrm{C}$ rise in temperature, lower rainfall in eastern districts, and a $0.5 \mathrm{~m}$ rise in sea level. Likely impacts on the rural sector include the southward movement of crop types, the introduction of subtropical crops, an increase in the growing season, the shortening of crop maturation times, and an increase in the frost-free area. Water supplies may dwindle in eastern areas and more frequent, damaging cyclones might increase on-farm costs. Sea level rise may affect drainage in coastal areas and contaminate aquifers. Pests and weeds may increase in number and type. Strategic planning at farm and regional level is vital to accommodate the change.

Keywords greenhouse gases, global warming, climate change, strategic planning, rural change

\section{INTRODUCTION}

Temperatures worldwide have now risen by nearly $1{ }^{\circ} \mathrm{C}$ in the past century and most scientific opinion suggests that such a warming is attributable directly to such activities as the burning of fossil fuels, industrial pollutants, deforestation and increasing areas of wetland food production (UNEP 1985). What is more alarming is that, with no change in these activities, the rate of increase in global temperatures is accelerating, so that within a century overall temperatures could be more than $5^{\circ} \mathrm{C}$ higher than at present. The potential impacts of such change are so serious that the issue of how to restrict the rise in temperature and how to cope with the impacts of the inevitable warming are now matters of both national and international concern (Pearce 1989a) (Figure la).

\section{THE COMPOSITION OF THE} ATMOSPHERE

Above the surface of the earth is an invisible blanket of gases, water vapour and dust particles comprising the atmosphere and extending to an altitude of 80 $\mathrm{km}$. The composition of the atmosphere is dominated by two gases, nitrogen and oxygen, the volume of which remains constant at $78 \%$ and $21 \%$ respectively. Nitrogen is essentially a bulking gas but is fixed by certain bacteria to enhance plant growth. Although oxygen is vital to most life forms and also aids in a variety of chemical and physical processes, its quantity remains constant because the amount used is exactly balanced by that returned to the atmosphere by plants.
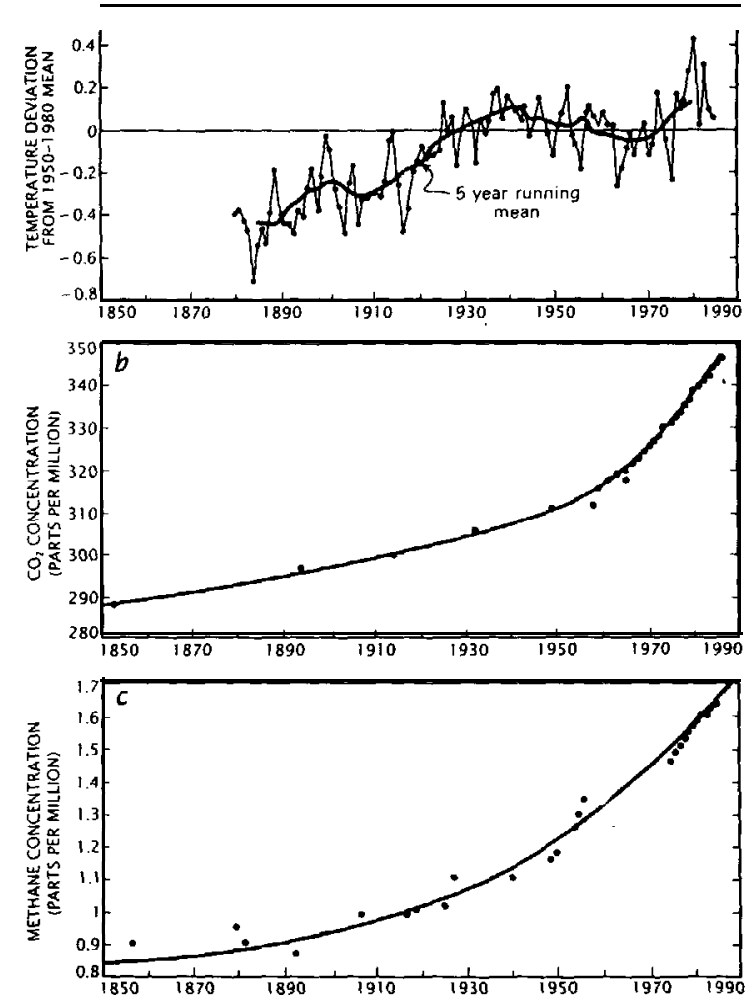

Figure 1 The close relationship of global temperature change (a) and the heat-trapping gases, carbon dioxide (b) and methane (c), since 1850 is clearly shown. (Source: Houghton \& Woodwell 1989).

The remaining $1 \%$ is a veritable atmospheric cocktail including the inert gases argon, neon, helium, krypton and xenon, most of which is argon. The remaining fraction is made up of hydrogen, carbon dioxide, methane and nitrous oxide. The last three, although they comprise less than 400 parts per million in total, have been variable throughout time and are now the centre of interest at the moment because of their impact on the atmospheric heat budget.

\section{KEEPING WARM}

One of the fundamental characteristics of the atmosphere is that by virtue of its varied 
composition, it has a range of absorptivities to both incoming and outgoing radiation. The earth receives both light and heat from the sun in the form of solar radiation, The radiation spectrum is changed by its passage through the atmosphere, including the interception of most of the damaging X-ray and ultra-violet radiation in the ozone layer and the reflection and absorption of some of the remaining visible light. When the remaining visible light is intercepted by water vapour in clouds, the amount of solar radiation reaching the surface is even further reduced.

If all the energy received at the surface of the earth was reradiated, the earth would have an average temperature of $-23^{\circ} \mathrm{C}$. However, because the received energy is absorbed at the surface and in the atmosphere, it is reradiated as longer-wave radiation (infra-red). The atmosphere is transparent to some of this but semi-transparent and opaque to most of it, largely because of the presence of water vapour, carbon dioxide, methane and other trace gases which, because of their various spectral absorptivities, prevent it from returning to space.

Although these gases comprise a minute proportion of the atmosphere, they play an essential part in maintaining global temperature at its current average of $15^{\circ} \mathrm{C}$. Because they act in a similar fashion to the glass in a greenhouse by allowing light (short-wave solar energy) in and preventing some of the heat (long wave terrestrial energy) from escaping, they are termed greenhouse gases and their action in the atmosphere is the greenhouse effect. Of course, the basic latitudinal imbalance of incoming and outgoing radiation is redressed by global wind systems and ocean currents constantly transporting the surplus heat of the tropics to the polar regions.

\section{HUMANKIND UPSETS THE BALANCE}

During the period before human society had any impact on the world's environment, the normal concentration of carbon dioxide in the atmosphere was 180-260 ppm, oscillating closely with global changes in temperature. By the time Cook had voyaged to New Zealand in 1769, the concentration had already risen to $280 \mathrm{ppm}$ and when global monitoring began in 1958, the figure had reached $315 \mathrm{ppm}$. At the moment, it is close to $350 \mathrm{ppm}$ and rising at $1.5 \%$ per year (Pearman 1988) (Figure $\mathrm{lb)}$.

Recent measurements show methane concentrations of $1.7 \mathrm{ppm}, 11 \%$ higher than a decade ago and 2.4 times higher than they have ever been in the past 160,000 years. Added to the fact that molecule-for-molecule, methane traps 20 times more infrared radiation than carbon dioxide,- its impact is far more important (Bishop 1988; Pearce 1989b) (Figure 1 c).

Measurements of other gases such as nitrous oxide, sulphur dioxide and the man-made chloro- fluorocarbons all show substantial increases over relatively short time spans, and coupled with methane, currently account for $40 \%$ of the greenhouse effect, predicted to rise to $50 \%$ as methane concentrations rise (Tucker 1988).

Why are such changes in the quantity of these gases occurring? Most of the carbon dioxide increase is caused by the burning of fossil fuels (oil, gas, coal) which releases carbon from long term storage into the atmospheric flux and which cannot be assimilated as quickly by the ocean-atmosphere system (Figure 2). Additionally, deforestation also changes carbon stored in the biosphere into atmospheric carbon, adding to the amount needed to be exchanged by the oceans. Methane is vented from the ground during mining operations, is produced in the gut of ruminant animals, is released from natural wetlands and paddy fields, and is a byproduct of termites. Nitrous oxide results from breakdown of nitrogenous fertilisers which are also produced from hydrocarbons. All these result from human activities and reflect anthropocentric actions to provide food and energy for a burgeoning world population (Houghton \& Woodwell 1989).

\section{WHAT CAN WE EXPECT?}

The upshot of these changes is believed to be an increase in world temperature beyond the 0.5 to $1.0^{\circ} \mathrm{C}$ change already experienced in the last 100 years. The change could range from 1.5 to $4.5^{\circ} \mathrm{C}$ by the year 2030, depending on steps taken to reduce the global production of greenhouse gases and the impacts of feedback mechanisms operating within the earth/biosphere/atmosphere/ocean system (RSNZ 1988). Scientists believe that global warming might have the following effects in New Zealand (MfE 1988):

1. An accelerating warming trend with a temperature rise of 0.5 to $1.0^{\circ} \mathrm{C}$ higher than present by 2025 and from 1.0 to $2.0^{\circ} \mathrm{C}$ higher by 2050 . Winter temperatures are likely to rise faster in southern districts and western districts are likely to experience milder overnight temperatures relative to daytime temperatures. The present mean annual temperature difference is $6^{\circ} \mathrm{C}$ from Northland to Southland and the largest annual variability is $2 \%$. This means that a $2^{\circ} \mathrm{C}$ increase in mean annual temperature is the equivalent of a northwards latitudinal shift of $4^{\circ} \mathrm{N}$ (or one-third of the country); the coldest years would be similar to the warmest years yet experienced.

2 . With the warming of the surrounding oceans, the frequency and intensity of tropical cylones (and the subsequent tropical depressions) might increase, affecting the North Island more than the South Island.

3. Prevailing westerly winds might decrease, especially in winter, and the systems would have more of a northerly component in them than at present. 
Figure 2 The annual global flux of carbon (shown in units of one billion metric tons) shows that the system is not quite in balance. Photosynthesis is balanced by plant and soil respiration. Although physicochemical processes at the sea surface absorb 4 billion tons more than is released, the 2 billion tons from deforestation and the 5 billion tons from the burning of fossil fuels result: in an atmospheric gain of 3 billion tons annually. The inset table lists the world's major carbon reservoirs. (Source: Houghton \& Woodwell 1989)

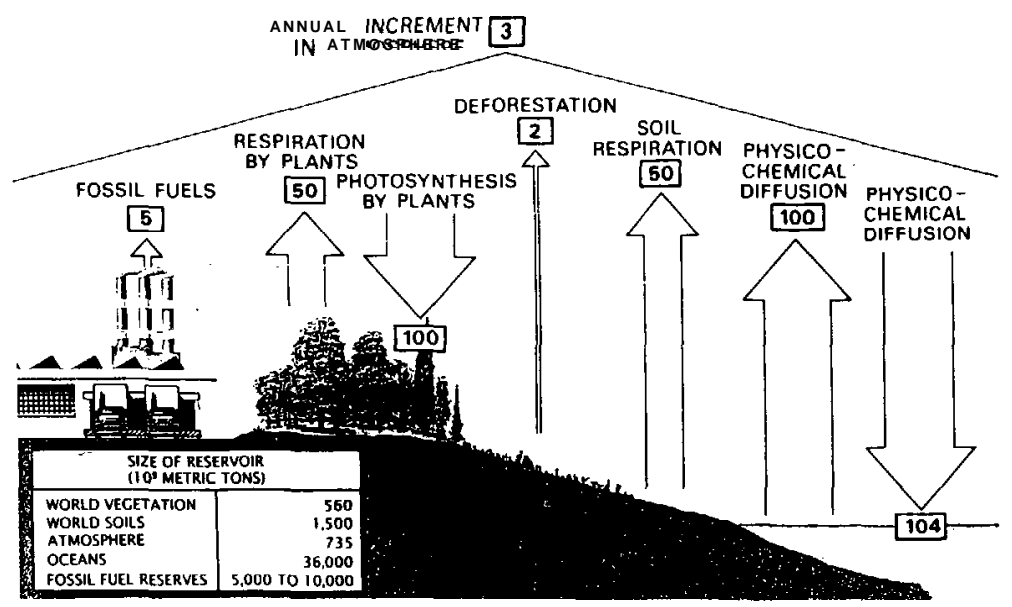

maintenance and fertility on these areas. A decrease in the number of chilling units (a measure of plant physiological requirements to initiate bud development) is also likely to push the northern limit of pip, stone and berry fruits southwards, especially in coastal areas where winter temperatures are already mild.

3. If temperature rises result in reduced yields, active plant breeding programmes may produce strains or cultivars to offset losses. Such plant breeding programmes may well also offer opportunities for increased diversification of crops.

4. Changes in the precipitation regime are probably the most difficult to predict, given that the country already has inherent variability associated with 'El Nino/Southern Oscillation events, 1 1-year rainfall cycles, periodic storminess, varying levels of frontal activity and the effect of topography on rainbearing wind systems. Any long term changes to annual precipitation totals are likely to be much less than the present inter-annual variability and thus will be within the present limits of farmer experience. The more far-reaching impact may be the effect of reduced rainfalls, especially on the east coasts of both islands, on soil moisture, water tables, ground water, deep aquifers and discharge of rivers, all of which the rural sector depends on for stock water and the maintenance and supplementation of plant growth. East coast localities are already taxing water supplies to the limit, and any benefits accruing from increased temperatures may be negated by the decreasing availability of water. Changing seasonal disposition of rainfall, with greater winter rainfall, may increase spring grass production but result in longer periods of nil to low grass growth during the summer. Using present conditions, a 10\% drop in precipitation usually reduces plant growth by 15 days. However, since grass growth begins to slow well before soil moisture deficit conditions occur, an increase in near-deficit conditions could reduce pasture production even more than is suggested. 5. Suggestions have been made that intensity and frequency of extra-tropical cyclones may increase, 
especially in the North Island. With the recent legacy of Cyclone Bola still very much evident, rural areas may well ponder how they will cope with the physical damage and economic cost of increasing storminess. Cyclones of the intensity of Bola occur on average about once every 20 years. If that reduces to once in 10 or even 5 years, farmers would need to budget for the costs of such events as well as the government making provision for increased disaster relief funding.

6. Sea level is not expected to rise more than 50 $\mathrm{cm}$ in the next half century but the rate of increase towards the end of the period may be close to the maximum that the coastal system can accommodate without major changes. Farms in some coastal localities may suffer increased coastal erosion or localised flooding. The major impact will be the increased levels of water tables in low-lying areas, greater problems with drainage and the possible incursion of sea water into aquifers. The last-named could be even more serious in areas such as the Heretaunga Plains if increased demand is placed on underground water supplies because of reduced rainfalls.

7. Weeds seem to thrive when temperatures rise and competition from weeds in both pastures and crops is likely to increase, and even new competitors may emerge in the changing conditions. While chemicals may be used, vigorous weed competition may force changes in land use.

8. Pests and fungous diseases may also increase, giving rise to additional control problems. The rise of new pests may restrict exports to particular destinations.

9. The enhancement of plant growth, especially of the $\mathrm{C} 3$ plants, because of the increased availability of carbon dioxide, is well documented from laboratory experiments but how plants cope in an open environment is less clearly understood. Since plants become more moisture efficient with increased levels of carbon dioxide, moisture demand may decline. Trees may invade tussock country which at present is too dry to support trees. Growth of Pinus radiata is likely to sustain a $5-10 \%$ increase over the 30 -year tree life, especially in warm, dry, sunny areas (Hollinger 1987).

10. The economic impact of all these changes should not be under-rated. New Zealand farmers are noted for their innovation and recent changes to the economic environment have certainly shown this. Any change in predominant land use in an area often requires a whole new infrastructure for processing its production. Any major change away from a high-intensity land use such as orchards may see the early obsolescence of coolstores, packhouses, processing and transport facilities. Changes here will also be matched by changes overseas and careful note needs to be made of what our competitors (and future competitors) are growing so that world markets are not saturated with unwanted produce.

\section{CONCLUSION}

In the short term, monthly, seasonal and annual variability will be significantly more important to the rural sector than will any long term changes in climate. Farming practice, decisions and productivity outcomes will still reflect the short term impact of the vagaries of weather and the seasonal climate that it produces.

However, in the longer term, decisions which have greater potential for economic gain or loss, or decisions which are strategic and so control the future direction of a farm's or a region's activities, may need to be carefully planned. Future outcomes should not be prejudiced or precluded by short term planning and incremental decision-making. Complementary to this should be an integration of planning policies at all levels of decision-making from the farm through regional to national levels of government.

Change in climate is almost inevitable. An acknowledgement of this and of the need to use the information propitiously to cope with uncertainties is the only sure way to ensure that the detrimental economic, social and environmental impacts are minimised while maximising new opportunities.

\section{REFERENCES}

Bishop, Jerry E., 1988. New culprit is indicted in greenhouse effect: rising methane level, Wall Street Journal, 24 0 ctober.

de Freitas, C.R. 1987. Perspectives on the impact of shortterm climatic change in New Zealand, New Zealand G eographer 43: 169-1 76 .

Hollinger, D.Y. 1987. Impact of rising levels of atmospheric $\mathrm{CO}$, on New Zealand's forests. What 's New in Forest Research 148.

Houghton, Richard A., Woodwell, George, M. 1989. Globa climate change, Scientific American, April. 260(4) 18-26.

MfE (Ministry for the Environment) 1988. Climate Change - the New Zealand Response, 264pp. Wellington: MfE.

Pearce, Fred, 1989a, Turning up the Heat -0 ur Perilous Future in the Global Greenhouse. London: Bodley Head.

Pearce, Fred, 1989b, Methane: the hidden greenhouse gas, New Scientist, 6 May: 19-23.

Pearman, G.I. 1988. Greenhouse gases: evidence for atmospheric changes and anthropogenic causes. In G.I. Pearman (ed.), Greenhouse Planning for Climate Change pp. 3-21. CSIRO, Australia.

RSNZ (Royal Society of New Zealand) 1988. Climate Change in New Zealand, 28pp. RSNZ, Wellington.

Salinger, M.J. 1987. Impact of climatic warming on the New Zealand growing season, Journal of the Royal Society of New Zealand 17(4):363-371.

Tucker, G.B. 1988. Climate modelling: how does it work? In G.I. Pearman fed.)., Greenhouse - Planning for Climate Change:' pp. 22-34. CSIRO, Australia.

UNEP (United Nations Environment Programme), 1985. Joint UNEP/WMO/ICSU Statement on 1985 Villach Conference on 'An assessment of the role of carbon dioxide and of other greenhouse gases in climate variations and associated impacts'. 